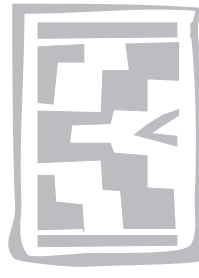

\title{
Ultrastructural features of the follicular wall in developing follicles of the sexually immature ostrich (Struthio camelus)
}

M-C. MADEKUROZWA ${ }^{1}$ and W.H. KIMARO ${ }^{2}$

\begin{abstract}
MADEKUROZWA, M-C. \& KIMARO, W.H. 2006. Ultrastructural features of the follicular wall in developing follicles of the sexually immature ostrich (Struthio camelus). Onderstepoort Journal of Veterinary Research, 73:199-195

The ultrastructure of the follicular wall in primordial, previtellogenic and vitellogenic follicles of the sexually immature ostrich is described in the present study. The follicular wall consists of a zona radiata, granulosa cell layer, basal lamina and thecal layer. Cytoplasmic processes from the plasma membranes of the granulosa cell layer and the ovocyte form the zona radiata in previtellogenic and vitellogenic follicles. The granulosa cell layer transforms from simple cuboidal epithelium in primordial follicles to simple columnar or pseudostratified columnar epithelium in previtellogenic and vitellogenic follicles. Transosomes were observed along the apical and lateral plasma membranes of granulosa cells. The thecal layer in previtellogenic and vitellogenic follicles consists of interna and externa components. The fibroblasts in the theca externa contain microfilaments, which are thought to be actin filaments.

The study revealed ultrastructural features, which are associated with the transportation of yolk precursors and nutrients into the ovoplasm. In addition, the study indicates that, although the cells in the theca externa contain microfilaments, they do not possess the ultrastructural characteristics of smooth muscle cells.
\end{abstract}

Keywords: Electron microscopy, follicles, ostrich, ovary, ultrastructure

\section{INTRODUCTION}

The ultrastructure of the wall of avian ovarian follicles has been extensively studied in the domestic fowl (Bellairs 1965; Wyburn, Aitken \& Johnson 1965a; Wyburn, Johnson \& Aitken 1965b; Dahl 1971; Rothwell \& Solomon 1977; Perry, Gilbert \& Evans 1978a, b; Yoshimura \& Koga 1982 ), the domestic goose (Kovacs, Forgo \& Peczely 1992) and the Japanese

1 Department of Anatomy and Physiology, Faculty of Veterinary Science, University of Pretoria, Private Bag X04, Onderstepoort, 0110 South Africa. E-mail: madex@op.up.ac.za

2 Department of Veterinary Anatomy and Cell Biology, Faculty of Veterinary Medicine, Sokoine University of Agriculture, P.O. Box 3016, Morogoro, Tanzania

Accepted for publication 6 April 2006-Editor quail (Ito, Kihara, Nakamura, Yonezawa \& Yoshizaki 2003). These studies have highlighted marked developmental changes in the ultrastructure of the zona radiata, perivitelline, granulosa and thecal components of the follicular wall.

The precocious development of the ovary and oviduct in the sexually immature ostrich has been described (Madekurozwa 2002a, b, 2004, 2005). A more recent histological and immunohistochemical study demonstrated the presence of primordial, previtellogenic and vitellogenic developing follicles in the active ovary of the sexually immature ostrich (Madekurozwa \& Kimaro in press). Primordial follicles are composed of an oocyte surrounded by a layer of flat granulosa cells. The granulosa cells are enclosed in a single layer of squamous thecal cells. 
A simple columnar or pseudostratified columnar granulosa cell layer surrounds the oocyte in previtellogenic follicles. The thecal layer in previtellogenic follicles is undifferentiated. Yolk accumulation is evident in the oocytes of vitellogenic follicles. A simple cuboidal cell layer surrounds the oocyte of these follicles. The thecal layer of vitellogenic follicles is clearly differentiated into theca interna and theca externa.

There is currently a paucity of information on the morphology of ovarian follicles in the sexually immature ostrich. Thus, the present study was undertaken to investigate the ultrastructure of ovarian follicles in this species. The results of this study complement the findings of the histological and immunohistochemical study carried out recently (Madekurozwa \& Kimaro in press).

\section{MATERIALS AND METHODS}

A total of 26 sexually immature female ostriches were used in the present study. The birds, which originated from commercial farms, were aged between 12 and 14 months, and weighed $90-100 \mathrm{~kg}$. At a commercial abattoir the ostriches were electrically stunned and exsanguinated. Ovarian tissue was immersion-fixed in $2.5 \%$ glutaraldehyde in $0.1 \mathrm{M}$ cacodylate buffer. Thereafter, the tissue samples were post-fixed in osmium tetroxide, dehydrated and embedded in epoxy resin. Ultrathin sections were stained with lead citrate and uranyl acetate. The samples were viewed with a Philips CMIO transmission electron microscope.

\section{RESULTS}

The ovary contained primordial, previtellogenic and vitellogenic follicles. The follicular wall enclosing the ovocyte was composed of four layers: the zona radiata; granulosa cell layer; basal lamina and thecal layer (theca interna and theca externa).

\section{Zona radiata}

The zona radiata is the region in which cytoplasmic processes from the granulosa cells and the ovocyte interdigitate. In primordial follicles the zona radiata was poorly developed (Fig. 1). In previtellogenic and vitellogenic follicles the zona radiata consisted of long, interdigitating cytoplasmic processes (Fig. 2). Interestingly, not all the granulosa cells exhibited cytoplasmic processes. In addition, in some cells only the peripheral regions of the apical membrane displayed cytoplasmic processes (Fig. 3).

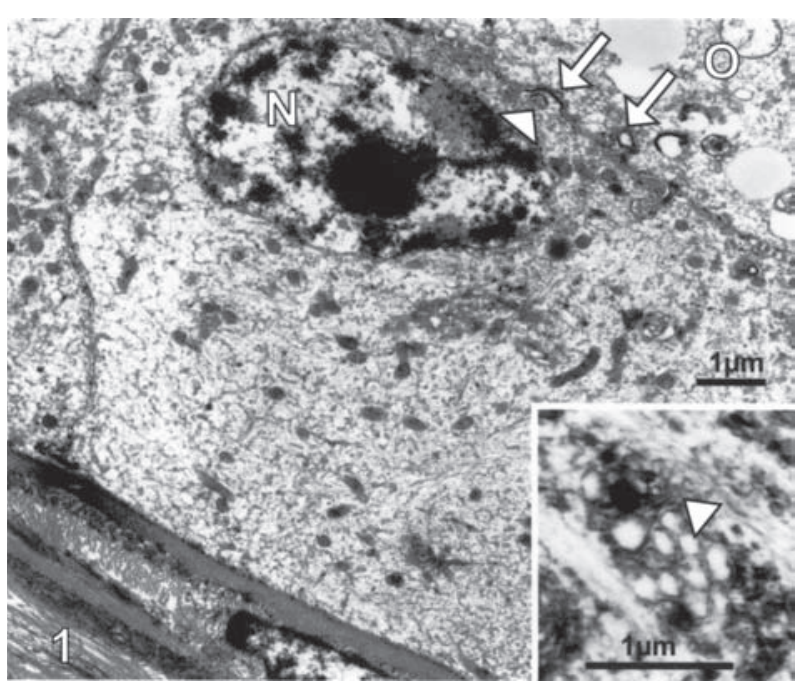

FIG. 1 A simple cuboidal granulosa cell in a primordial follicle. The relatively smooth apical plasma membrane displays a few transosomes (arrows). Note the presence of a vesicle (arrowhead) below the evaginating transosome. $\mathrm{N}$ : nucleus. O: ovocyte

Inset: A multivesicular body (arrowhead) in the granulosa cell of a primordial follicle

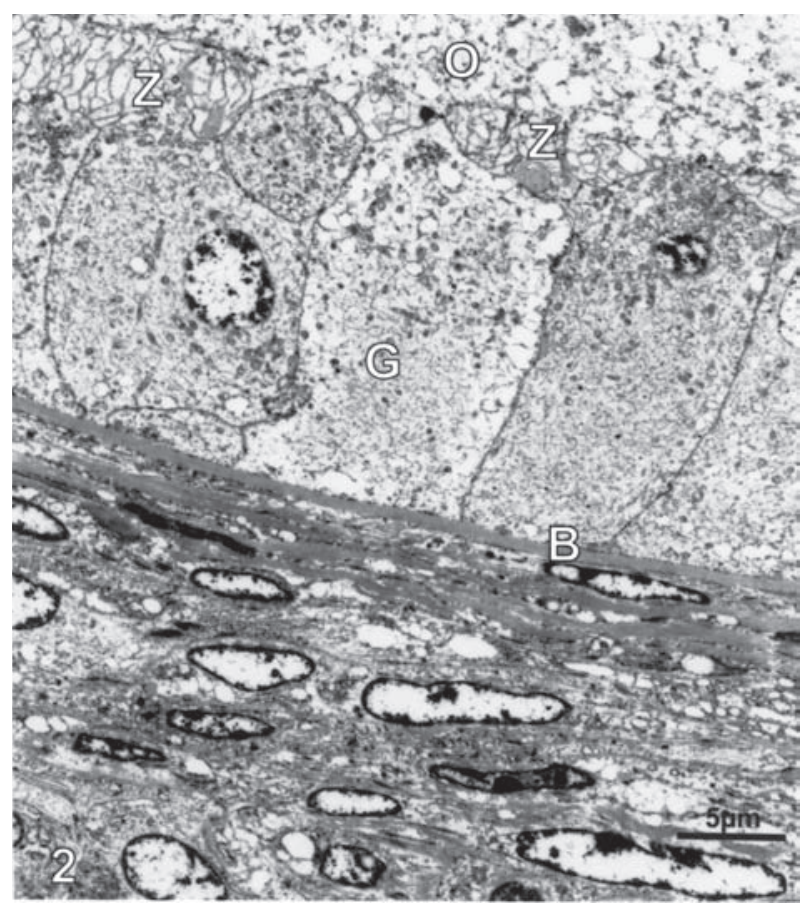

FIG. 2 Part of the follicular wall and ovocyte $(\mathrm{O})$ of a previtellogenic follicle. Cytoplasmic processes from granulosa cells and the ovocyte form the zona radiata $(Z)$. The granulosa cell layer $(G)$ is composed of a simple columnar epithelium. B: basal lamina

\section{Perivitelline layer}

The perivitelline layer is an amorphous substance located between the cytoplasmic processes forming 


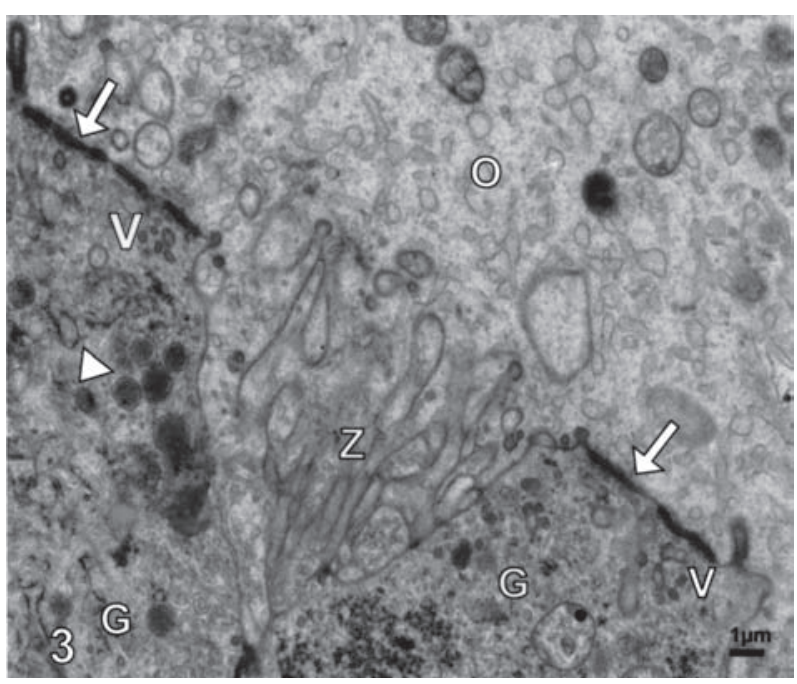

FIG. 3 Apical portion of a granulosa cell. Note the peripheral localization of the zona radiata $(Z)$. The sub-apical cytoplasm contains numerous vesicles (V) and electron dense bodies (arrowhead). Desmosomes (arrows) attach the granulosa cell plasma membrane to the oolemma. O: ovocyte. G: granulosa cells

the zona radiata. None of the follicles studied in the present investigation exhibited a perivitelline layer.

\section{Granulosa cell layer}

A simple cuboidal granulosa cell layer surrounded the ovocyte in primordial follicles (Fig. 1). In previtellogenic and vitellogenic follicles, the granulosa cell layer was composed of either a simple columnar or a pseudostratified columnar epithelium (Fig. 2). Granulosa cells in primordial follicles were characterized by the presence of an ovoid, heterochromatic nucleus, with a prominent nucleolus (Fig. 1). The spherical nucleus observed in previtellogenic and vitellogenic cells was either centrally or apically-located (Fig. 2).

The cytoplasm in primordial follicles contained relatively few organelles, which included mitochondria, rough endoplasmic reticulum (RER) cisterns, electron dense bodies, transosomes and multivesicular bodies (Fig. 1). In addition, a dense network of microfilaments was observed in the cytoplasm. The subapical cytoplasm in previtellogenic and vitellogenic follicles contained numerous mitochondria, electron dense bodies and vesicles (Fig. 3 and 4). Some of the electron dense bodies contained membranes, which appeared to be remnants of transosomes (Fig. 4). Large amounts of RER and numerous vacuoles were also a typical feature of the granulosa cells in previtellogenic and vitellogenic follicles. In addition, occasional lipid droplets were observed in these cells.

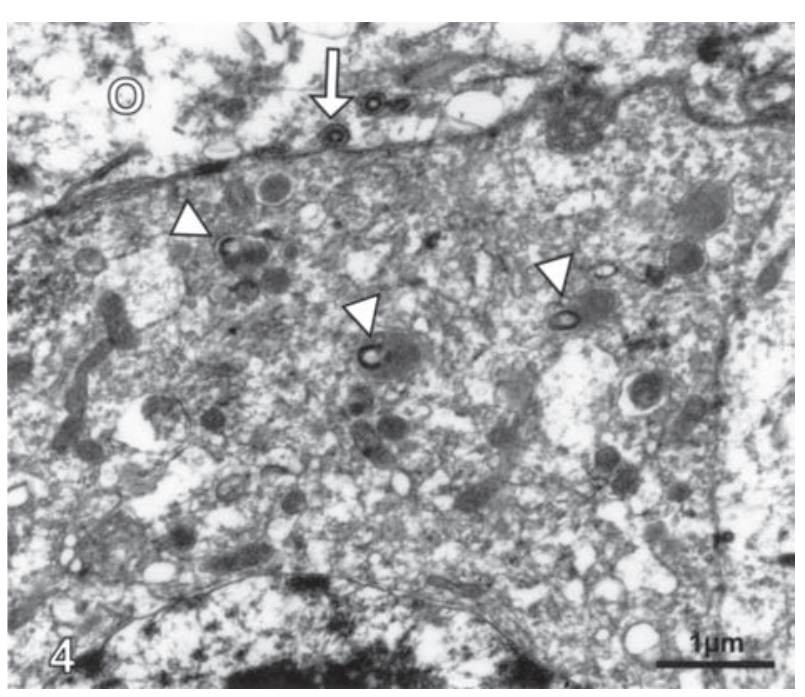

FIG. 4 Supranuclear cytoplasm of a granulosa cell in a previtellogenic follicle. The apical plasma membrane exhibits transosomes (arrow). Electron dense bodies (arrowheads) within the granulosa cell contain transosomes. O: ovocyte

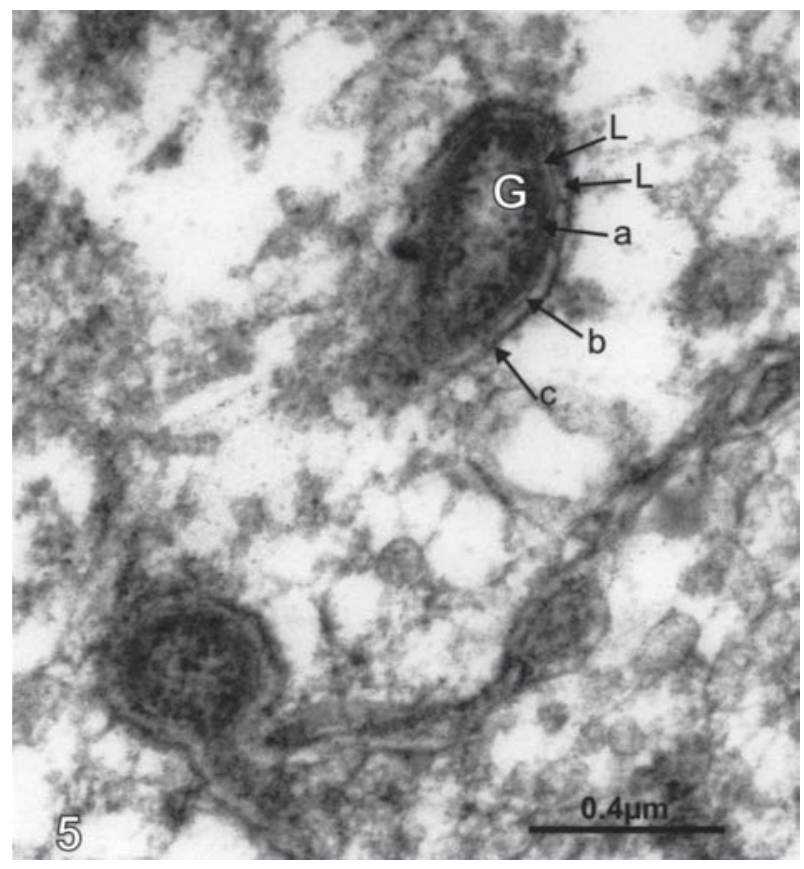

FIG. 5 The transosomes formed from the apical plasma membrane are composed of inner (a), middle (b) and outer (c) membranes. Granules $(G)$ line the inner membrane. Electron lucent $(L)$ areas occur between the inner and middle membranes, as well as between the middle and outer membranes

In all follicles desmosomes attached the apical plasma membrane of the granulosa cells to the ovocyte plasmalemma (Fig. 3). Transosomes were observed along the apical and lateral plasma membranes of the granulosa cells. Transosomes along the apical 


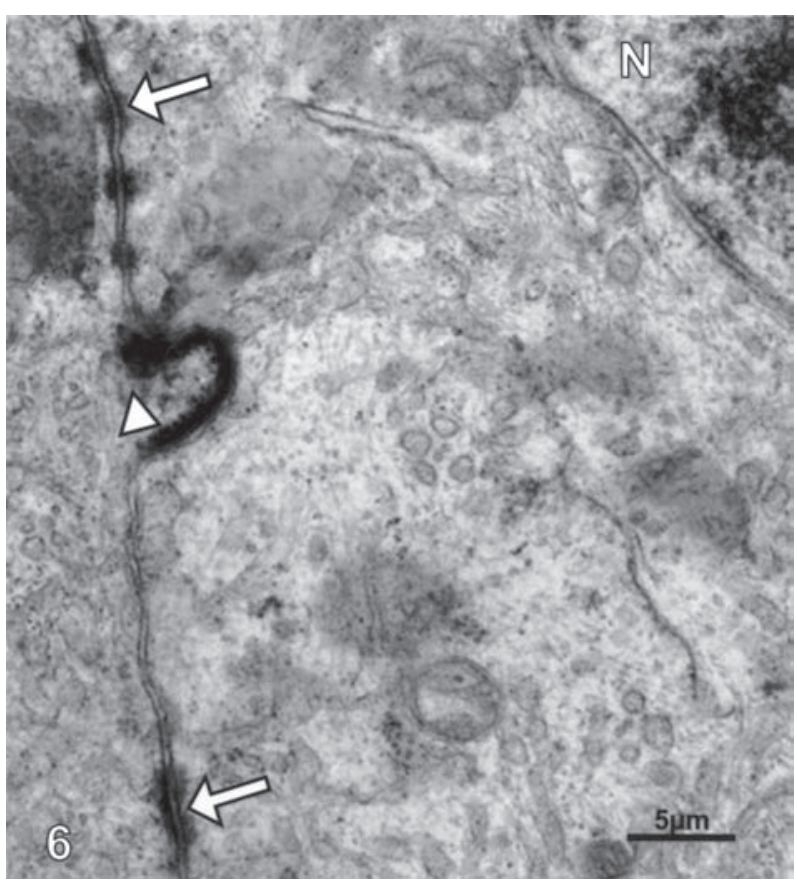

FIG. 6 Transosomes formed along the lateral plasma membranes of the granulosa cells are composed of a single electron dense membrane lined with granules (arrowhead). Arrows: desmosomes. N: nucleus

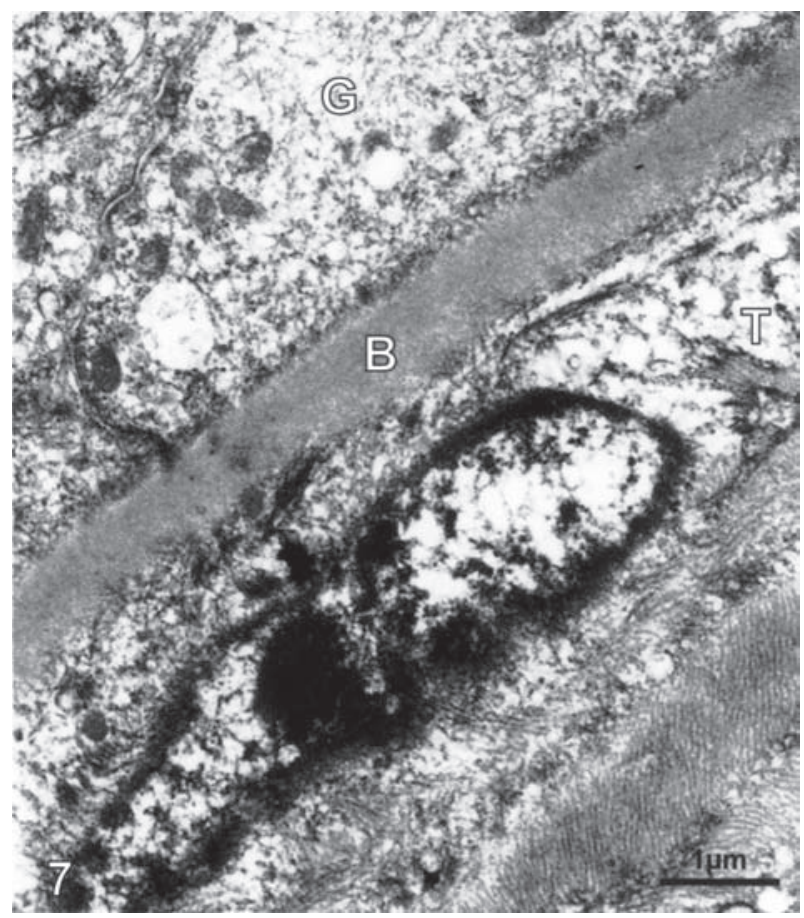

FIG. 7 A homogeneous basal lamina (B) separates the granulosa cells $(G)$ from the thecal fibrocytes $(T)$

plasma membrane were most numerous in areas devoid of cytoplasmic processes. In the early stages of transosome formation a focal, electron dense area



FIG. 8 Portion of a vitellogenic follicle. Fibrocytes (arrows) with elongated, heterochromatic nuclei form the theca interna. Theca externa contains fibroblasts (arrowheads) and interstitial endocrine cells $(\mathrm{T})$ separated by dense accumulations of collagen fibres (asterisks). B: blood vessel

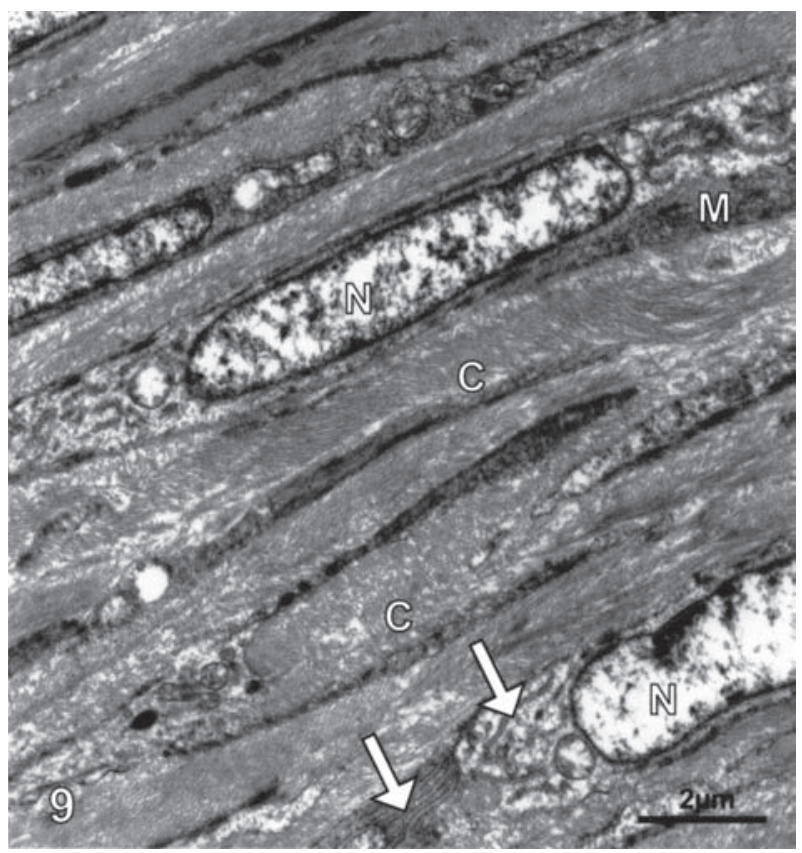

FIG. 9 Photomicrograph of the theca externa showing fibroblasts with elongated nuclei $(\mathrm{N})$. The cytoplasm contains long cisterns of RER (arrows) and microfilaments (M). C: collagen fibres

of the granulosa cell plasma membrane evaginated. Directly below the evaginating apical membranes were vesicles with electron dense membranes (Fig. 


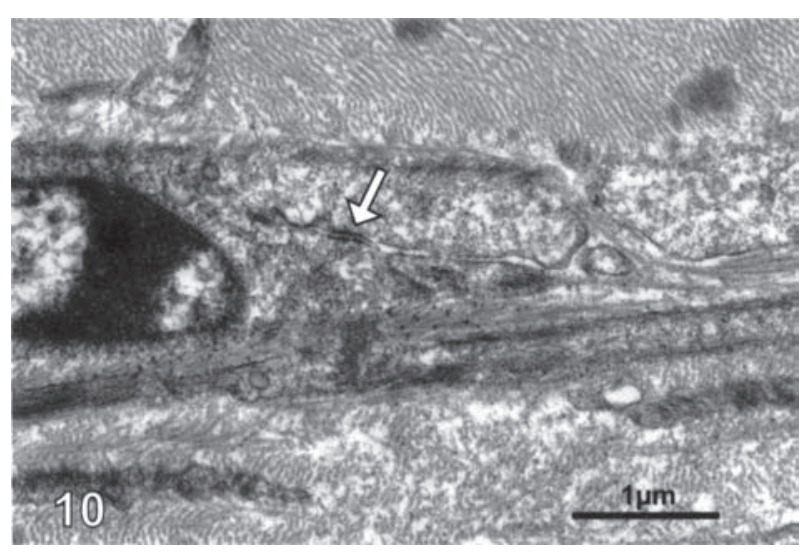

FIG. 10 Desmosomes (arrow) connected some of the fibroblasts in the thecal layer

1). Upon release into the ovoplasm, the transosomes consisted of three electron dense layers, with the inner and middle, as well as the middle and outer layers separated by electron lucent areas. Electron dense granules lined the inner layer of the transosome (Fig. 5). Transosomes, which formed along the lateral plasma membranes, were composed of a single electron dense membrane lined with granules (Fig. 6).

\section{Basal lamina}

The granulosa cell layer and thecal layer were separated by a homogeneous basal lamina, which was approximately $1 \mu \mathrm{m}$ thick. The boundary between the basal lamina and the cells of the thecal layer was not well defined (Fig. 7).

\section{Thecal layer}

The thecal layer in primordial follicles consisted of two to three layers of fibrocytes. In previtellogenic and vitellogenic follicles the thecal interna was composed of fibrocytes with elongated, heterochromatic nuclei (Fig. 8). The cytoplasm contained mitochondria, RER profiles and a few lipid droplets. The fibroblasts in the theca externa of previtellogenic and vitellogenic follicles contained elongated, euchromatic nuclei. These fibroblasts were characterized by the presence of long, parallel profiles of RER.

In addition, the peripheral regions of the cytoplasm contained numerous microfilaments (Fig. 9). Collagen fibres separated the layers of fibroblasts within the theca externa. Fibroblasts within the same layer were commonly connected by desmosomes (Fig. 10). Several blood vessels, nerves and interstitial endocrine cells were observed in the thecal layer.

\section{DISCUSSION}

Based on the structure of the follicular wall it is evident that its primary function is the transportation of yolk precursors to the ovocyte. The transfer of yolk precursors from the granulosa cell layer to the ovocyte is aided by the presence of the zona radiata and transosomes.

The zona radiata is composed of long Interdigitating cytoplasmic processes, which effectively increase the surface area available for nutrient transfer. This is supported by research carried out on the domestic fowl in which it was shown that the zona radiata was most prominent during the period of rapid yolk deposition (Rothwell \& Solomon 1977). In the current study, the zona radiata in the primordial follicles was poorly developed, implying that at this stage of development there is a limited movement of yolk precursors into the ovoplasm. Conversely, the long cytoplasmic processes forming the zona radiata in previtellogenic and vitellogenic follicles suggested that the transfer and formation of yolk material was active in these follicles. The observation in the current study of an unevenly distributed zona radiata in previtellogenic and vitellogenic follicles is unusual, as research conducted in the domestic fowl (Wyburn et al. 1965a; Wyburn, Johnson \& Aitken 1966; Rothwell \& Solomon 1977; Perry et al. 1978a), domestic goose (Kovacs et al. 1992) and dove (Zarnescu 2004) has demonstrated the presence of an evenly distributed zona radiata in previtellogenic and vitellogenic follicles. Ultrastructural studies will need to be conducted on the follicles in sexually mature ostriches to determine whether the uneven distribution of the zona radiata is peculiar to this species.

Avian ovarian follicles contain membranous organelles known as transosomes which are involved in the transportation of the yolk precursors vitellogenin into the ovocyte (Ito et al. 2003). Transosomes are also known as unique organelles (Schjeide, Munn, McCandless \& Edwards 1966), terminal membranes (Wyburn et al. 1965b), coated vesicles (Perry et al. 1978a) and lining bodies (Bellairs 1965; 1967; Greenfield 1966; Paulson \& Rosenberg 1974; Ito et al. 2003; Zarnescu 2004). Based on the observation that transosomes also form between adjacent granulosa cells it is probable that these organelles are responsible for the transfer of nutrients between cells. As is the case in the domestic fowl (Bellairs 1965; Wyburn et al. 1965b; Schjeide, Hanzely, Holshouser \& Briles 1974; Rothwell \& Solomon 1977) and the domestic goose (Kovacs et al. 1992), transosomes in the sexually immature ostrich were present in all 
follicular sizes. In the present study, transosomes formed in areas of the apical granulosa cell, which were devoid of cytoplasmic processes. In contrast, transosomes in the domestic goose (Kovacs et al. 1992) and the Japanese quail (Ito et al. 2003) form at the tips of granulosa cell cytoplasmic processes. The morphology of transosomes in the ovarian follicles of the sexually immature ostrich was similar to that described in the domestic fowl (Wyburn et al. 1965b; Schjeide et al. 1966, 1974; Schjeide, Kancheva, Hanzely \& Briles 1975), the domestic goose (Kovacs et al. 1992) and the dove (Zarnescu 2004). The inner membrane of the transosome was lined by granules, which have been described as being "ribosome-like" (Kovacs et al. 1992; Paulson \& Rosenberg 1974; Zarnescu 2004). However, Bellairs (1965) has stated that the granules are much larger than ribosomes. Thus, the exact composition of the granules lining the inner membrane of transosomes is still unknown. The outermost layer of the transosome is derived from the ovocyte plasmalemma. It is unclear whether the middle layer of the transosome originates from the ovocyte plasmalemma or from the plasma membrane of the granulosa cell.

It is known that the basal lamina plays an important role in the movement of yolk precursors from capillaries in the thecal layer to the granulosa cell layer. Callebaut (1990) has reported the presence of yolk precursors and lipid droplets in the basal lamina of preovulatory follicles in the Japanese quail. It was thought that the yolk precursors were en route from the thecal capillaries to the granulosa cell layer. Although a close association between the fibrocytes in the thecal layer and the basal lamina was noted, no lipid droplets were observed in the basal lamina of the sexually immature ostrich.

The thecal layer contains numerous capillaries, which act as a final conduit of yolk precursors from the liver. In addition to its role in nutrient transportation, the externa component of the thecal layer probably plays a role in the ovulation process of the mature follicle. Controversy surrounds the cells forming the theca externa. Researchers have described the cells in the theca externa as being "fibroblast-like" (Perry et al. 1978a; Zarnescu 2004) or "smooth muscle-like" (Van Nassauw, Callebaut, Harrisson \& Scheuermann 1992). Contrary to the observations made in the Japanese quail (Van Nassauw et al. 1992), the theca externa cells in the sexually immature ostrich did not display any ultrastructural features typical of smooth muscle cells. The findings of our previous study have shown that the cells in the theca externa are immunohistochemically distinct from the cells in the theca interna and stroma (Madekurozwa \& Kimaro, in press). The theca externa showed strong smooth muscle actin immunoreactivity, whereas the fibroblasts in the stroma were immunonegative for smooth muscle actin. Very few cells in the theca interna showed smooth muscle actin immunoreactivity. Based on these findings it is probable that the dense meshwork of microfilaments observed in the present study were actin microfilaments. Perry et al. (1978a) have suggested that the fibroblasts in the thecal layer have contractile abilities, which enable them to play a role in the rupture of the follicular wall during ovulation.

In conclusion, the results of the present study have shown that the ultrastructure of developing follicles in the sexually immature ostrich is similar, but not identical to that of other avian species. The absence of the perivitelline layer in the ovarian follicles of the sexually immature ostrich is a notable difference. The amorphous material forming the perivitelline layer has been shown to be vitellogenin (Ito et al. 2003). Thus, the absence of the perivitelline layer in the sexually immature ostrich suggests that the transfer of vitellogenin from the granulosa cells into the ovocyte is very low at this stage of development.

\section{ACKNOWLEDGEMENTS}

The authors thank the staff in the Electron Microscope Unit for their technical assistance. The University of Pretoria and the National Research Foundation funded this study. The Deutscher Akademischer Austauschdienst (DAAD) is gratefully acknowledged for providing Dr W.H. Kimaro with a scholarship, which enabled him to pursue a Master's degree at the University of Pretoria.

\section{REFERENCES}

BELLAIRS, R. 1965. The relationship between oocyte and follicle in the hen's ovary as shown by electron microscopy. Journal of Embryology and Experimental Morphology, 13:215233.

BELLAIRS, R. 1967. Aspects of the development of yolk spheres in the hen's oocyte, studied by electron microscopy. Journal of Embryology and Experimental Morphology, 17:267-281.

CALLEBAUT, M. 1990. Improved visualization of ultrastructural components in the avian ovarian granulosa basement membrane. Cell Biology International Reports, 14:653-658.

DAHL, E. 1971. The fine structure of the granulosa cells in the domestic fowl and rat. Zeitschrift für Zellforschung, 119:5867.

GREENFIELD, M.L. 1966. The oocyte of the domestic chicken shortly after hatching, studied by electron microscopy. Journal of Embryology and Experimental Morphology, 15:297316. 
ITO, Y., KIHARA, M., NAKAMURA, E., YONEZAWA, S. \& YOSHIZAKI, N. 2003. Vitellogenin transport and yolk formation in the quail ovary. Zoological Science, 20:717-726.

KOVACS, J., FORGO, V. \& PECZELY, P. 1992. The fine structure of the follicular cells in growing and atretic ovarian follicles of the domestic goose. Cell and Tissue Research, 267: 561-569.

MADEKUROZWA, M-C. 2002a. Progesterone and oestrogen receptor immunoreactivity in the vagina of the immature ostrich, Struthio camelus. British Poultry Science, 43:450-456.

MADEKUROZWA, M-C. 2002b. A study of the immunohistochemical localization of the progesterone and oestrogen receptors in the magnum of the immature ostrich, Struthio camelus. Anatomia Histologia Embryologia, 31:317-320.

MADEKUROZWA, M-C. 2004. Immunohistochemical localization of the progesterone and oestrogen receptors in the shell gland of sexually immature ostriches (Struthio camelus) with active and inactive ovaries. Research in Veterinary Science, 76:63-68.

MADEKUROZWA, M-C. 2005. Morphological features of the luminal surface of the magnum in the sexually immature ostrich (Struthio camelus). Anatomia Histologia Embryologia, 34:350-353.

MADEKUROZWA, M-C. \& KIMARO, W.H. 2006. A morphological and immunohistochemical study of healthy and atretic follicles in the ovary of the sexually immature ostrich (Struthio camelus). Anatomia Histologia Embryologia (in press).

PAULSON, J.L. \& ROSENBERG, M.D. 1974. Formation of lining bodies and oocyte bodies during avian oogenesis. Developmental Biology, 40:366-371.

PERRY, M.M., GILBERT, A.B. \& EVANS, A.J. 1978a. Electron microscope observations on the ovarian follicle of the domestic fowl during the rapid growth phase. Journal of Anatomy, 125:481-497.

PERRY, M.M., GILBERT, A.B. \& EVANS, A.J. 1978b. The structure of the germinal disc region of the hen's ovarian follicle during the rapid growth phase. Journal of Anatomy, 127:379392.

ROTHWELL, B. \& SOLOMON, S.E. 1977. The ultrastructure of the follicle wall of the domestic fowl during the phase of rapid growth. British Poultry Science, 18:605-610.

SCHJEIDE, O.A., MUNN, R.J., McCANDLESS, R.G. \& EDWARDS, R. 1966. Unique organelles of avian oocytes. Growth, 30: 471-489.

SCHJEIDE, O.A., HANZELY, L., HOLSHOUSER, S.J. \& BRILES, W.E. 1974. Production and fates of unique organelles (transosomes) in ovarian follicles of Gallus domesticus under various conditions. Cell and Tissue Research, 156:47-59.

SCHJEIDE, O.A., KANCHEVA, L., HANZELY, L. \& BRILES, W.E. 1975. Production and fates of unique organelles (transosomes) in ovarian follicles of Gallus domesticus under various conditions. II. Cell and Tissue Research, 163:63-79.

VAN NASSAUW, L., CALLEBAUT, M., HARRISSON, F. \& SCHEUERMANN, D.W. 1992. Smooth muscle cells in the walls of ovarian follicles in the Japanese quail. Cell and Tissue Research, 269:49-56.

WYBURN, G.M., AITKEN, R.N.C. \& JOHNSON, H.S. 1965a. The ultrastructure of the zona radiata of the ovarian follicle of the domestic fowl. Journal of Anatomy, 99:469-484.

WYBURN, G.M., JOHNSON, H.S. \& AITKEN, R.N.C. 1965b. Specialised plasma membranes in the preovulatory follicle of the fowl. Zeitschrift für Zellforschung, 68:70-79.

WYBURN, G.M., JOHNSON, H.S. \& AITKEN, R.N.C. 1966. Fate of the granulosa cells in the hen's follicle. Zeitschrift für Zellforschung, 72:53-65.

YOSHIMURA, Y. \& KOGA, O. 1982. Ultrastructural changes of the stigma of the follicle during the process of ovulation in the hen. Cell and Tissue Research, 224:349-359.

ZARNESCU, O. 2004. Ultrastructural observations of previtellogenic ovarian follicles of dove. Zygote, 12:285-292. 